BACKGROUnD: Production of antibodies that are specific for allergens is an important pathological process in inflammatory allergic diseases. These contain the antibodies against antigens of Candida albicans, one of the normal microbial flora in an intestinal tract. We studied the effects of the prednisolone administration on the production of anti-Candida antibodies in the gastrointestinally $C$. albicans-colonized mice.

Methods and Materials: BALB/c mice, treated with antibacterial antibiotics to decontaminate indigenous intestinal bacterial flora, were inoculated intragastrically with $C$. albicans. The mice, in which $C$. albicans grows intestinally, were administered prednisolone to induce temporary immunosuppression. The Candida growth in their intestinal tract and their antibody response to Candida were examined.

Results: Antibiotic treatment allowed establishment of $C$. albicans gastrointestinal colonization, but did not cause subsequent systemic dissemination of $C$. albicans in all the animals. When these animals received an additional treatment with prednisolone, they showed a significantly higher population of $C$. albicans in their feces than those of animals treated with antibiotics alone, and the organisms were recovered even from their kidney. This systemic dissemination by $C$. albicans appeared to be temporal, because all the mice survived without any symptoms for more than 2 months. Examination of the serum titers of total immunoglobulin (Ig)E antibodies and specific IgE and IgG antibodies against Candida antigens demonstrated that titers of total IgE increased, partially by day 14 and clearly at day 27 , in prednisolone-treated Candida-colonized mice. Without prednisolone treatment, an increment of the serum titer was scarcely observed. By day 27 , corresponding to the increase of total IgE, the antiCandida IgE and IgG titer increased in mice of the prednisolone-treated group.

Conclusion: Administration of prednisolone to Candida-colonized mice can induce production of the IgG, IgE antibodies against Candida antigens, perhaps through temporal systemic dissemination of Candida from the intestinal tract.

Key words: Candida albicans, Gut colonization, Immunoglobulin E antibody

\section{Production of anti-Candida antibodies in mice with gut colonization of Candida albicans}

\author{
Shigeru Tansho ${ }^{1, C A}$, Shigeru Abe ${ }^{2}$, \\ Hiroko Ishibashi ${ }^{2}$, Masayasu Mitsuya ${ }^{1}$, \\ Kayoko Wada', Tatsuo Ikeda', Nobuo Suegara', \\ Osamu Koshio ${ }^{1}$, Yasuo Ono ${ }^{1}$ and \\ Hideyo Yamaguchi ${ }^{2}$
}

${ }^{1}$ Department of Microbiology and Immunology, Teikyo University School of Medicine, 2-11-1 kaga Itabashi-ku Tokyo 173-8605, Japan and ${ }^{2}$ Teikyo University Institute of Medical Mycology, 359 Otsuka, Hachioji, Tokyo 192-0395, Japan

\footnotetext{
${ }^{\mathrm{CA}}$ Corresponding Author

Tel: +81339641211

Fax: +8135375 5284

E-mail: stansho@med.teikyo-u.ac.jp
}

\section{Introduction}

Candida albicans is known to be one of the intestinal microbial flora of healthy persons. ${ }^{1}$ To this microbe, adults elicit cellular and/or humoral immune responses postulated to have some pathogenetic relevance to such allergic diseases as atopic dermatitis $(\mathrm{AD})^{2-7}$ and food allergy. ${ }^{8}$ Savolainen et al. reported that $\mathrm{AD}$ patients frequently have a high titer of anti- $C$. albicans antibodies in their sera.? Candida organisms are colonized in the intestinal tracts in these patients and are harbored in the nasal cavity and buccal capsule in a saprophytic manner at high frequency, and a high titer of immunoglobulin (Ig)E antibody reacting with Candida is frequently detectable.? Moreover, several recent examples have shown that oral administration of antifungal agents to AD patients has displayed therapeutic efficacy with improvement of dermatitis. ${ }^{4,10,11}$

To study the pathogenetic roles of $C$. albicans in these allergic diseases, it is important to analyze the induction process of anti-Candida IgE and/or IgG antibodies in Candida-colonized individuals. However, it is not yet known how specific Candida IgE 
antibodies are produced in modern human life. We assumed that intestinal translocation of Candida organisms might provide immunogenic stimulation to produce specific IgE and/or IgG antibodies. We reported previously that application of antibiotics and anti-inflammatory corticosteroids induced an overgrowth of $C$. albicans in the intestinal tract of mice. ${ }^{12}$ Here, we find that prednisolone treatment of mice intestinally colonized by $C$. albicans induced production of specific IgE and IgG antibodies, perhaps through systemic dissemination of this fungus from the gut.

\section{Materials and methods}

\section{Preparation of Candida inoculate for challenge}

C. albicans TIMM 0239 $9^{12,13}$ was grown in Sabouraud dextrose broth in an L-tube. After growing at $37^{\circ} \mathrm{C}$ overnight, cells were harvested by centrifugation, washed three times with saline, and adjusted to a cell density appropriate for inoculation to mice.

\section{Animals and inoculation}

All animal experiments were performed according to the guidelines for the care and use of animals approved by Teikyo University. To produce intestinally $C$. albicans-colonized mice, we used a modified method of Uchida et al. ${ }^{13}$ Specific pathogen-free female BALB/c mice, 6-8 weeks old (Japan SLC, Inc., Shizuoka, Japan) were given potable water containing $1 \mathrm{mg} / \mathrm{ml}$ of ampicillin (Meiji Seika Co., Tokyo, Japan) and $0.2 \mathrm{mg} / \mathrm{ml}$ of kanamycin (Meiji Seika Co.) until the end of the experiments. Each mouse was challenged intragastrically with $1 \times 10^{6}$ cells of $C$. albicans at a volume of $0.1 \mathrm{ml}$ using a gastric gavage. For immunosuppression, animals were subcutaneously given $100 \mathrm{mg} / \mathrm{kg}$ body weight of prednisolone (Mitaka Seiyaku, Tokyo, Japan) 7 and 9 days after the Candida challenge as described elsewhere. $^{12}$ Intestinal colonization of $C$. albicans was monitored by counts of viable $C$. albicans cells in their stools as follows. Every stool sample was homogenized in a volume of sterile saline and serial 10-fold dilutions with saline were made. One hundred microliters of each dilution was inoculated onto Candida GS agar (Tanabe Seiyaku Co. Ltd, Osaka, Japan) and the cultures were incubated at $37^{\circ} \mathrm{C}$ for 24 $\mathrm{h}$, at which time quantitation of fungal colonies was performed. In some experiments, Candida-challenged mice were killed for microbial examination; kidneys were excised aseptically and homogenized in a glass tissue grinder with $1 \mathrm{ml}$ of saline. Viable Candida cells were counted as already described, and the results were expressed as the mean \pm standard deviation value of colony-forming units (CFU) per kidneys of five mice in each group.

\section{Enzyme-linked immunosorbent assay}

The total IgE level was measured by a sandwich enzyme-linked immunosorbent assay (ELISA) using two kinds of rat anti-mouse IgE monoclonal antibody (mAb) (6HD5 and HMK12) according to the instructions of the manufacturer (Yamasa Shoyu Co., Ltd., Choshi, Japan). ${ }^{14}$ These mAbs recognized different epitopes of Fc fragments of murine IgE. Briefly, 96 wells of solid immunomicroplates (Nunc) were coated with $50 \mu \mathrm{l}$ of $6 \mathrm{HD} 5 \mathrm{mAb}(5 \mu \mathrm{l} / \mathrm{ml})$ and blocked with phosphate-buffered saline supplemented with $1 \%$ bovine serum albumin (Sigma Chemical Co., St Louis, MO, USA). Collected samples or standard mouse IgE (SPE7; Seikagaku Kogyo, Tokyo, Japan) were added to the wells and incubated for $1 \mathrm{~h}$ at room temperature. Each well was washed with phosphate-buffered saline containing $0.05 \%$ Tween-20, and received $50 \mu \mathrm{l}$ of biotinylated HMK12 mAb $(1 \mu \mathrm{g} / \mathrm{ml})$, and then all the plates were incubated for $1 \mathrm{~h}$. After $50 \mu \mathrm{l}$ of peroxidase-conjugated avidin (1/2000; Dakopatts, Glostrup, Denmark) was added to each well, another $1 \mathrm{~h}$ incubation was carried out. Finally, the reaction products were visualized with $0.4 \mathrm{mg} / \mathrm{ml}$ of orthophenylenediamine (Sigma) and $0.012 \% \mathrm{H}_{2} \mathrm{O}_{2}$. Thirty minutes after addition of the substrate, the reaction was stopped with $0.05 \mathrm{ml}$ of $0.2 \mathrm{M} \mathrm{H}_{2} \mathrm{SO}_{4}$ and the absorbance at $490 \mathrm{~nm}$ wavelength was measured by an Immunoreader (NJ-2300; Nippon Intermed, Tokyo, Japan). In this assay the minimal detectable concentration of IgE was $40 \mathrm{ng} / \mathrm{ml}$.

Specific IgE for Candida antigens was measured by an ELISA as described previously ${ }^{14}$ with slight modifications. A Candida antigen preparation was obtained from C. albicans cells by $37 \mathrm{C} 2 \mathrm{~h}$ incubation in $0.05 \mathrm{M}$ citrate buffer ( $\mathrm{pH} \mathrm{7)}$ as described elsewhere. $^{15-17}$ Immunomicroplates for ELISA (Nunc) were coated with the Candida antigen preparation (0.75 $\mu \mathrm{g}$ protein $/ \mathrm{ml})$. Serum samples were incubated in the Candida antigen-coated microwells for $1 \mathrm{~h}$. Then, binding of IgE antibodies with the Candida antigens was detected by rat anti-mouse IgE mAb (biotinylated HMK12 mAb) and peroxidase-conjugated avidin as already described.

\section{Statistical analysis}

Statistical difference in the survival rate was examined by Wilcoxon test. Other statistical analyses were examined by Student's $t$-test. 


\section{Results}

Effects of treatments with antibiotics and/or prednisolone on intestinal colonization of $C$. albicans in mice

The effects of treatments to mice with two antibacterial agents, ampicillin and kanamycin, and/or prednisolone on the intestinal colonization of $C$. albicans were examined. BALB/c mice taking antibacterial agent-supplemented or unsupplemented drinking water were orally infected with C. albicans. As shown in Fig. 1, viable Candida cells were recovered from the feces of the Candida-inoculated mice from the day following oral inoculation (day 1). On this day the mean CFU number of Candida in the stools of mice given the supplemented drinking water was about $1 \times 10^{5} \mathrm{CFU} / \mathrm{g}$ of stool. The viable Candida population in the stools of mice given the unsupplemented drinking water rapidly decreased to a level of less than $1 \times 10^{4} \mathrm{CFU} / \mathrm{g}$ on day 3 . On the other hand, antibiotic-treated mice maintained a high concentration of $C$. albicans of about $1 \times 10^{7} \mathrm{CFU} / \mathrm{g}$ for more than 2 weeks.

Figure 1 also shows that two subcutaneous administrations of prednisolone increased the CFU level about 10-fold in the antibiotic-treated mice. To check the systemic dissemination of C. albicans from intestinal colonization in these mice, their kidney homogenates of their kidney were cultured on Candida-GS-agar. As shown in Fig. 2, in mice treated with prednisolone at days 7 and 9, Candida cells were detected on day 11 and the number of CFU in

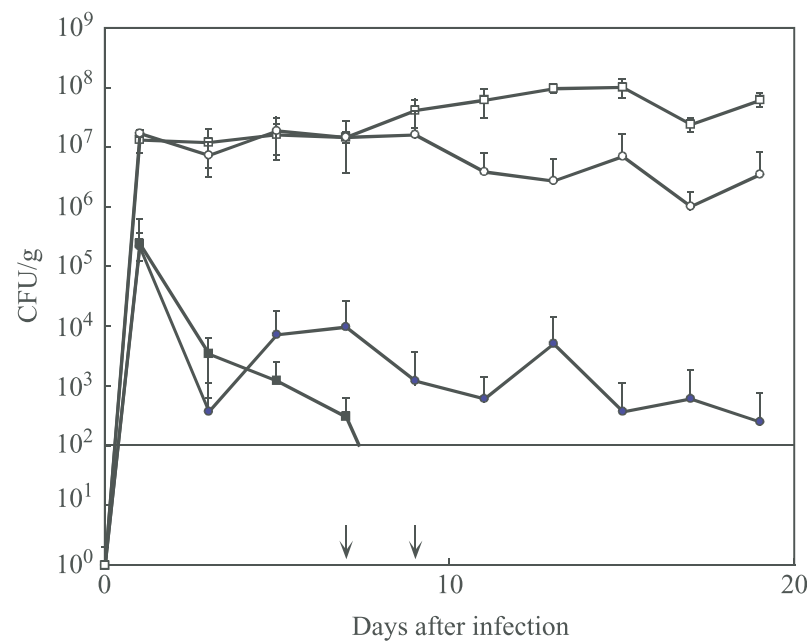

FIG. 1. Viable Candida cells in feces of $C$. albicans-infected mice treated with prednisolone. BALB/c mice were given potable water with (open symbols) and without antibiotic (closed symbols). Mice were infected with $10^{6} \mathrm{CFU}$ of $C$. albicans in their intestinal tracts, then were subcutaneously given $100 \mathrm{mg} / \mathrm{kg}$ of prednisolone (closed squares, open squares) or saline (closed circles, open circles) at 7 and 9 days after this infection, respectively. Feces counts were determined at time points thereafter. The results are expressed as a viable count obtained from groups of nine mice per data point.

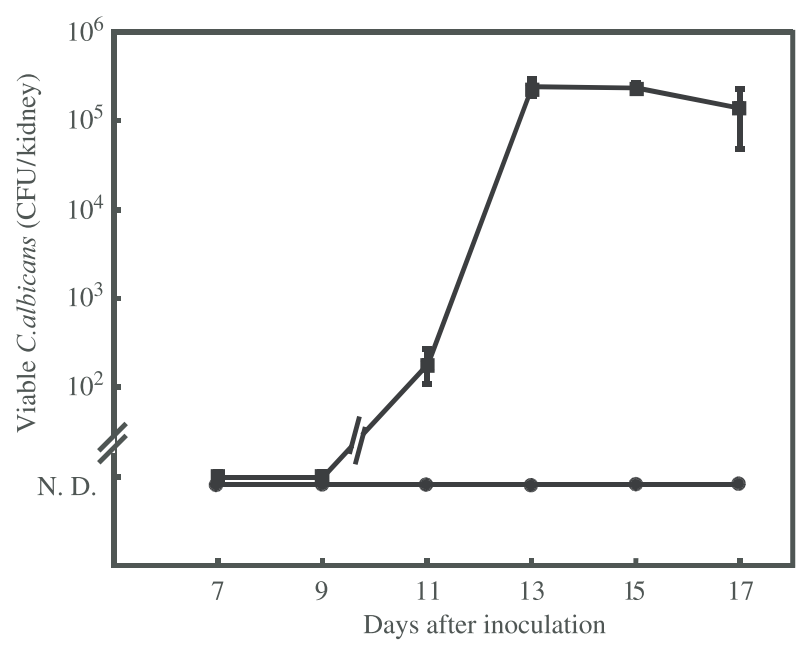

FIG. 2. Viable Candida cells in the kidney of C. albicansinfected mice treated with or without prednisolone. BALB/c mice were infected with $10^{6} \mathrm{CFU}$ of $C$. albicans in their intestinal tracts, then were subcutaneously given $100 \mathrm{mg} / \mathrm{kg}$ of prednisolone (squares) and Saline (circles) at 7 and 9 days after this infection. Candida cell counts in kidney were determined at time points thereafter. The results are expressed as a viable count obtained from groups of nine mice per data point.

their kidney increased to $5 \times 10^{5} \mathrm{CFU} / \mathrm{g}$ on day 13 , but the mice tested survived for more than 1 month. This indicates that the prednisolone treatment caused temporal systemic dissemination of C. albicans 2 weeks after the infection but did not result in Candida infection fatal to the hosts.

\section{Antibody-formation of orally Candida-infected mice with or without prednisolone treatment}

Total IgE concentration in sera of these Candidainfected mice at 2 and 4 weeks after Candida infection was measured. As shown in Fig. 3, in comparison with normal mice, a low but significant level of IgE (less than $100 \mathrm{ng} / \mathrm{ml}$ ) could be detected in the sera of the antibiotic-treated and Candidacolonized mice at 2 weeks after the challenge. Prednisolone treatments of such mice clearly increased the serum level of IgE of the animals to about $120 \mathrm{ng} / \mathrm{ml}$ and $200-300 \mathrm{ng} / \mathrm{ml}$ at 2 and 4 weeks after the challenge, respectively.

In further experiments, the titers of IgE and IgG antibodies against Candida antigen in the sera of the C. albicans-colonized mice at 4 weeks after the challenge were examined. Figures 4 and 5 show that IgE and IgG, respectively, against Candida antigens increased in the serum of the animals treated with antibiotics and infected orally with $C$. albicans and twice administered with prednisolone. Without the treatment with both prednisolone and antibiotics, these infected mice would had no sera showing a detectable level of antibodies against Candida antigens higher than those of control mice. 


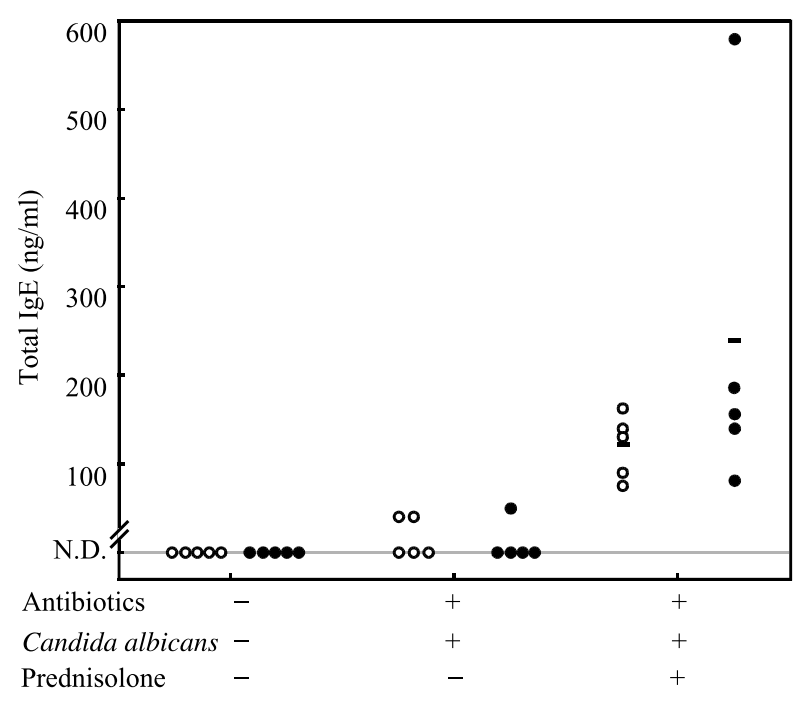

FIG. 3. Total serum IgE levels in C. albicans-infected mice treated with prednisolone. Serum levels were tested at 2 weeks (open circles) and 4 weeks (closed circles) after the Candida infections. Total IgE were measured using a specific ELISA as described in Materials and methods. Detection limits of total $\operatorname{lgE}$ were $40 \mathrm{ng} / \mathrm{ml}$. * $p<0.05$, when compared with the control (normal mouse serum).

These results indicated that prednisolone treatment caused a significant increase in specific Candida IgE and IgG antibodies in the sera of Candida-colonized mice.

\section{Discussion}

We have shown that prednisolone administration to mice with intestinally-colonized $C$. albicans induced IgG and IgE antibodies in their sera within 4 weeks after infection. As far as we know, this is the first report that administration of anti-inflammatory steroidal compounds causes production of anti-Candida antibodies in Candida-colonized animals. Antibody production augmented by prednisolone treatment is not curious, because immunosuppressive activity of prednisolone subcutaneously given in the deposuspension form is known to disappear within 1 week after administration.

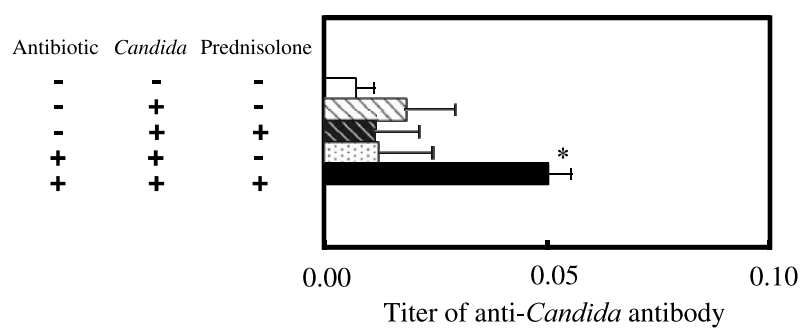

FIG. 4. Enhanced production of anti-Candida antibody (IgE) in sera of $C$. albicans-infected mice treated with prednisolone. Serum levels of antibodies were tested 4 weeks after the Candida infections. Specific IgE of anti-Candida antibody was measured using a specific ELISA as described in Materials and methods. Each value represents the mean \pm standard error of five mice per group. ${ }^{*} p<0.05$, when compared with the control (normal mouse serum).

The mechanism of the augmentation of antibody production by prednisolone remains to be clarified. We believe that prednisolone treatment must have a profound effect on the immunological condition of the mice, since the concentration of total IgE immunoglobulin in the sera clearly increased to 200-300 $\mathrm{ng} / \mathrm{ml}$ in prednisolone-treated Candida infected mice. We can speculate that the augmentation of anti-Candida IgE production by prednisolone treatment may result from in vivo antigen stimulation accompanied by temporal systemic dissemination of Candida from the intestinal tract, since Candida dissemination to kidney was observed in the Candida infected prednisolone treated mice at 6 days after prednisolone treatment, as shown in Fig. 2. This speculation is supported by the finding that no augmented production of IgE or IgG against Candida antigens was observed in either antibiotictreated or prednisolone-treated mice unless they had been orally inoculated with $C$. albicans (Figs 4 and 5)

The findings presented here may have some impact on the field of questions among clinical dermatologists of why steroidal anti-inflammatory drugs sometimes have a negative effect on the pathogenesis of $\mathrm{AD}$. AD shows chronic symptoms with clinical manifestation of repeated aggravating itching and high concentration of IgE in sera. In AD patients dermal mast cells bind with IgE; when these

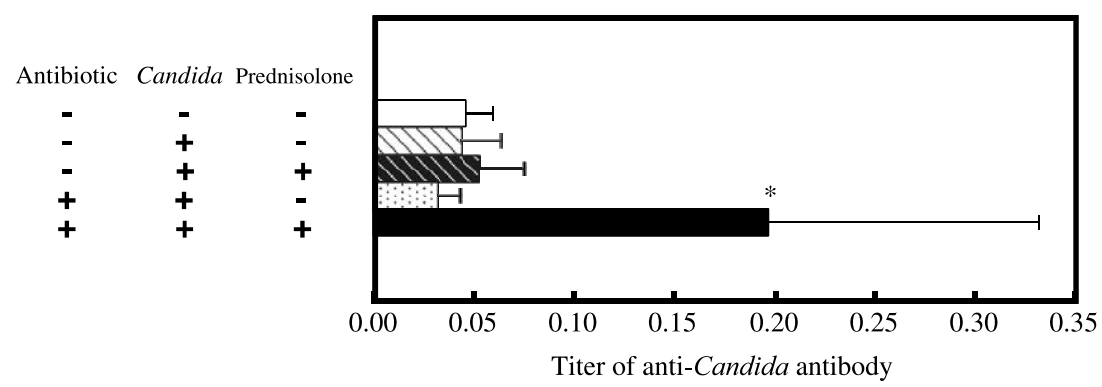

FIG. 5. Enhanced production of anti-Candida antibody (Ig G) in sera of C. albicans-infected mice treated with prednisolone. Serum levels of antibodies were tested 4 weeks after the Candida infections. Specific IgG of anti-Candida antibody was measured using a specific ELISA as described in Materials and methods. Each value represents the mean \pm standard error of five mice per group. ${ }^{*} p<0.05$, when compared with the control (normal mouse serum). 
IgE are bound with antigens, they release the chemical mediator histamine that induces pathological symptoms of edema and itching. Severe itching makes patients scratch their skin, perturbing/disturbing the epidermal organization of epidermal cells and destroying the barrier of the skin so that it is invaded by many allergens, worsening the dermatitis. These suggest that a high concentration of IgE in patient sera plays a critical role in the pathogenesis of $\mathrm{AD}$. Our results therefore mean that a steroidal antiinflammatory drug may have a severe pathogenic effect on AD patients because of the augmented production of IgE. However, at the present time, we cannot precisely explain the relationship among the administration of a steroid drug, intestinal translocation of Candida and pathogenesis of AD. To clarify this relation, we hope that our model in which antiCandida IgE production can be induced by prednisolone treatment will be used as a tool to analyze the relationships between anti-inflammatory agents and IgE allergy with Candida infection.

\section{References}

1. Odds FC. Candida and Candidosis, Saunders WB, ed. London: Balliere Tindall; 1988.

2. Akiyama K, Shida $\mathrm{T}$, Yasuega $\mathrm{H}$, et al. Allergenicity of acid protease secreted by Candida albicans. Allergy 1996; 51: 887-892

3. Kimura M, Tsuruta S, Yoshida T. IFN-gamma plays a dominant role in upregulation of Candida-specific IgE synthesis in patients with atopic dermatitis. Allergy. Clin Immunol 2000; 122: 195-199.

4. Kitamura K, Suga C, Onuma S. Efficacy of oral amphotericin B for refractory atopic dermatitis with specitic IgE to Candida albicans and food allergens in sera. Allergol Int 1997; 46: 125-133.
5. Nermes M, Savolainen J, Kalimo K, Lammintausta K, Viander M. Determination of IgE antibodies to Candida albicans mannan with nitrocellulose-RAST in patients with atpic diseases. Clin Exp Allergy 1994; 24: 318-323.

6. Savolainen J, Kortekangas-Savolainen $O$, Nermes $M$, Viander $M$ Koivikko A, Kalimo K, Terho EO. IgE, IgA, and IgG responses to common yeasts in atopic patients. Allergy 1998; 53: 506-512.

7. Savolainen J, Koivikko A, Kalimo K, Nieminen E, Viander M. IgE, IgA, and IgG antibodies and delayed skin response towards Candida albians antigens in atopic with and without saprophytic growth. Clin Exp Allergy 1990; 4: 332-339.

8. Petitpierre M, Gumowski P, Girard JP. Irritable bowel syndrome and hypersensitivity to food. Ann Allergy 1985; 54: 538-540

9. Savolainen J, Lammintausta K, Kalimo K, Viander M. Candida albicans and atopic dermatitis. Clin Exp Allergy 1993; 4: 332-339.

10. Adachi A, Horikawa T, Ichihashi M, Takashima T, Komura A. Role of Candida allergen in atopic dermatitis and efficacy of therapy with various antifungal agents. Arerugi 1999; 7: 719-725 (in Japanese).

11. Back B, Scheynius A, Johansson SG. Ketokonazole in atopic dermatitis: therapeutic response is correlated with decrease in serum IgE. Arch Dermatol Res 1995; 287: 448-451.

12. Tansho $\mathrm{S}$, Abe $\mathrm{S}$, Mizutani $\mathrm{S}$, Ono $\mathrm{Y}$, Takesako $\mathrm{K}$, Yamaguchi $\mathrm{H}$. Protection of mice from lethal endogenous Candida albicans infection by immunization with Candida membrane antigen. Microbiol Immunol 2002; 46: 307-311

13. Uchida K, Yamaguchi H, Shabby K. Thetherapeutic effects of itraconazole, a new triazole antifungal agent, on experimental fungal infections. Jpn J Antibiot 1991; 44: 588-599 (in Japanese).

14. Hirano T, Miyajima $\mathrm{H}$, Kitagawa $\mathrm{H}$, et al. Studies on murine IgE with monoclonal antibodies. Int Arch Allergy Appl Immun 1988; 85: 47-54.

15. Whelan WJ, Edwards FE. Isolation of yeast mannan: polysaccharides of Bakers' Yeast. Part IV, Mannan, Stanley Part. J Chem Soc 1961; 1: 29-34.

16. Okubo Y, Ichikawa T, Suzuki S. Relationship between phoshate content and immunochemical properties of subfractions of Bakers' Yeast mannan. J Bacteriol 1978; 136: 63-68.

17. Kobayashi H, Shibata N, Mikobe H, Okubo Y, Suzuki S. Stractual stady of phosphomannan of Yeast-form cells of Candida albicans J-1012 strain with special reference to application of mild acetolysis. Arch Biochem Biophys 1989; 272: 364-375.

Received 10 March 2004

Accepted 22 April 2004 


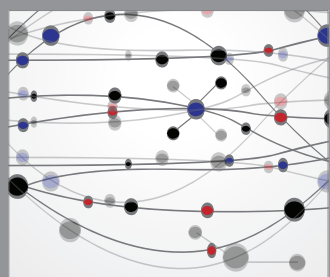

The Scientific World Journal
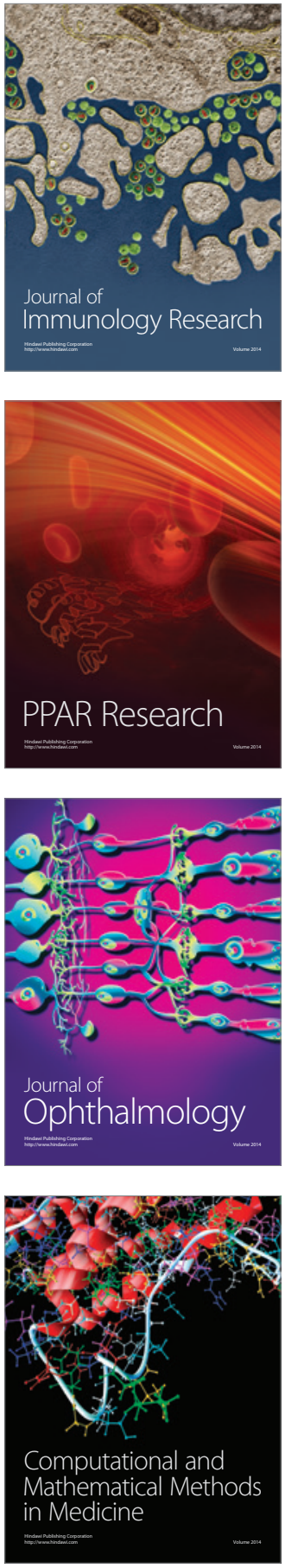

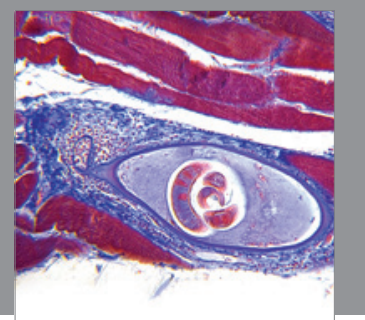

Gastroenterology

Research and Practice
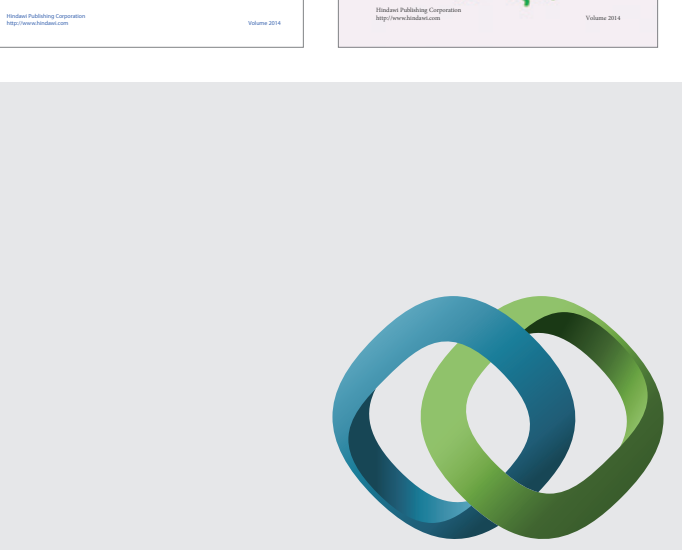

\section{Hindawi}

Submit your manuscripts at

http://www.hindawi.com
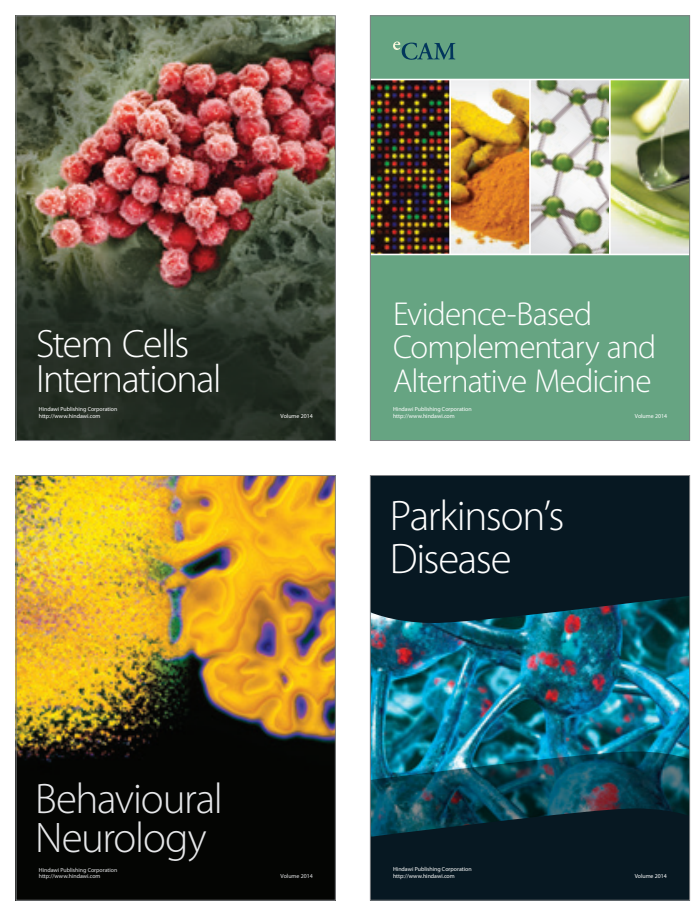

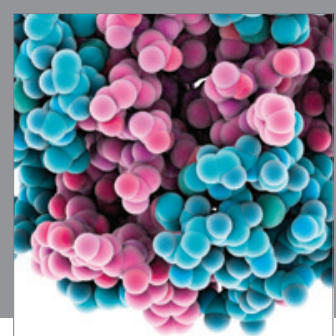

Journal of
Diabetes Research

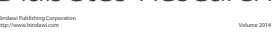

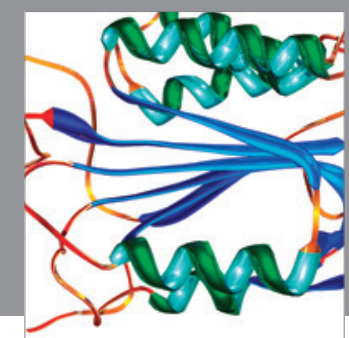

Disease Markers
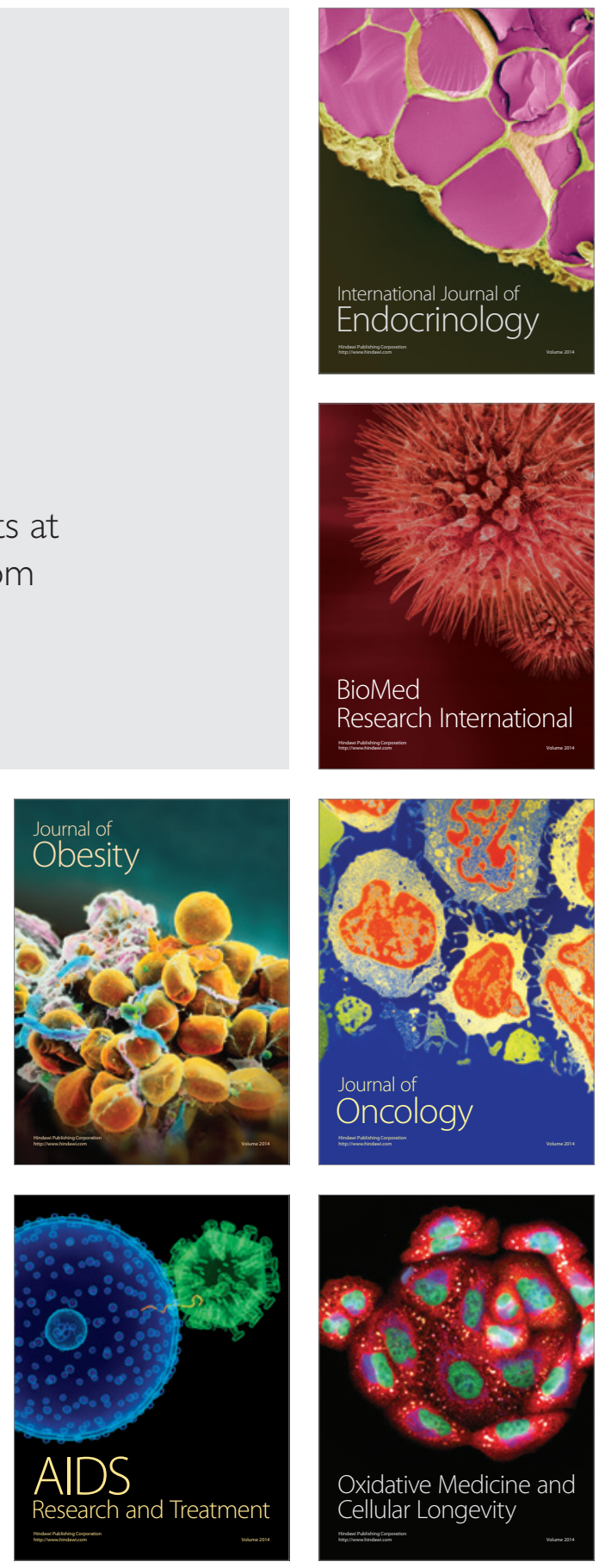